\title{
AVALIAÇÃO DO BEM-ESTAR DE FRANGOS DE CORTE EM DOIS GALPÕES COMERCIAIS CLIMATIZADOS
}

\author{
Evaluation of poultry well-being in two commercial climatized poultry houses \\ Flávio Alves Damascenoํㅜ, Tadayuki Yanagi Junior², Renato Ribeiro de Lima ${ }^{3}$, \\ Raphaela Christina Costa Gomes ${ }^{4}$, Sandra Regina Pires de Moraes ${ }^{5}$
}

\begin{abstract}
RESUMO
Objetivou-se, com esta pesquisa, avaliar as condições do ambiente interno em dois galpões comerciais de frangos de corte equipados com dois sistemas de resfriamento diferentes: placas porosas umedecidas de celulose associadas à nebulização (SRPN) e placas umedecidas de sombrite associadas à nebulização (SRSN). Nos galpões estudados, situados em Itaberaí, GO, foram avaliadas quatro variáveis térmicas (temperatura, índice de temperatura de globo negro e umidade, carga térmica de radiação e entalpia), três respostas fisiológicas (temperaturas retal e da pele, e frequência respiratória) e três índices de desempenho produtivo (ganho de peso, consumo de ração e conversão alimentar) das aves. Os resultados indicaram que os sistemas avaliados não foram suficientemente adequados para promover condições de conforto às aves, não sendo observada diferença estatística significativa entre o desempenho das aves neles alojados. A taxa de mortalidade no galpão SRSN foi 15\% maior em relação ao galpão SRPN, porém, ambas são inferiores àquelas sugeridas para as aves em estudo.
\end{abstract}

Termos para indexação: Frango de corte, conforto térmico, resposta fisiológica, desempenho produtivo.

\section{ABSTRACT}

The main goal of this study was to evaluate the environmental conditions inside two commercial broiler houses equipped with different cooling systems: wet cellulose pads associated with misting (SRPN) and wet black screen pads associated with misting (SRSN). In the studied broiler houses, located in Itaberaí, Goiás, Brazil, four thermal variables (temperature, black globe temperature and humidity indices, thermal radiation load and enthalpy), three physiological responses (rectal temperature, skin temperature and respiration frequency), and three productivity performance indexes (weight gain, feed intake and feed conversion) for broiler chickens were evaluated. The results indicate that the evaluated systems were not sufficient to promote thermal comfort conditions for the birds and in general, no significant statistical difference was noticed between the performances of the birds raised in the two broiler houses. The mortality rate in the SRSN system was 15\% higher than in the SRPN system, however, both are lower than those suggested for the birds under study.

Index terms: Broiler, thermal comfort, physiological responses, productive performance.

(Recebido em 18 de junho de 2009 e aprovado em 16 de março de 2010)

\section{INTRODUÇÃO}

A avicultura de corte vem se apresentando como uma das mais importantes fontes de proteína animal. Para isso, a produção de carne de frango no Brasil passou por um grande desenvolvimento nas últimas décadas, sendo que para atingir essa posição de destaque, uma série de fatores foram fundamentais, tais como a aquisição de novos conhecimentos específicos nas áreas de nutrição, genética, manejo e bem-estar das aves, permitindo que índices positivos fossem alcançados. Os fatores térmicos, representados principalmente pela temperatura do $\operatorname{ar}\left(\mathrm{t}_{\mathrm{bs}}\right)$, umidade relativa (UR), radiação térmica e velocidade do ar
(V), são aqueles que afetam mais diretamente as aves, pois podem comprometer a sua homeotermia. De acordo com Sainsbury (1971), Yousef (1985) e Medeiros (2001), de forma geral, a faixa de $\mathrm{t}_{\mathrm{bs}}$, UR e $\mathrm{V}$, que resultam em melhor desempenho animal, ocorrem entre $21^{\circ} \mathrm{C}$ e $27{ }^{\circ} \mathrm{C} ; 50 \%$ e $70 \%$, e $0,5 \mathrm{~m} \mathrm{~s}^{-1}$ e $1,5 \mathrm{~m} \mathrm{~s}^{-1}$, respectivamente.

De acordo com Baêta \& Souza (1997), existem vários índices para quantificar e avaliar o ambiente térmico dos animais, porém nas condições ambientais em que os animais são expostos à radiação solar, um dos indicadores mais precisos de estresse é o índice de temperatura de globo e umidade (ITGU), sendo que esse índice,

${ }^{1}$ Universidade Federal de Viçosa/UFV - Departamento de Engenharia Agrícola/DEA - Av. P.H. Rolfs - s/n -36.571-000 - Viçosa, MG flavio.damasceno@ufv.br

2Universidade Federal de Lavras/UFLA - Departamento de Engenharia/DEG - Lavras, MG

${ }^{3}$ Universidade Federal de Lavras/UFLA - Departamento de Ciências Exatas/DEX - Lavras, MG

${ }^{4}$ Universidade Federal de Goiás/UFG - Escola de Veterinária/EV - Goiânia, GO

5Universidade Estadual de Goiás/UEG - Anápolis, GO 
desenvolvido por Buffington et al. (1981), incorpora diretamente em um único valor, os valores de $t_{b s}, U R, V$ e a radiação solar na forma de temperatura de globo negro $\left(\mathrm{T}_{\mathrm{gn}}\right.$, em $\left.\mathrm{K}\right)$, podendo ser calculado de acordo com a equação 1 , em que, $\mathrm{T}_{\mathrm{po}}$ é a temperatura do ponto de orvalho, em K.

$\mathrm{ITGU}=\mathrm{T}_{\mathrm{gn}}+0,36 \cdot \mathrm{T}_{\mathrm{po}}-330,08$

Segundo Esmay (1974), outro parâmetro importante para a avaliação da condição ambiental é a carga térmica de radiação (CTR), que pode ser determinada pela equação 2, sendo que, s a constante de Stefan-Boltzmann $\left(5,6710^{-8}\right.$ $\mathrm{W} \mathrm{m}^{-2} \mathrm{~K}^{-4}$ ), $\mathrm{V}$ a velocidade do ar em $\mathrm{m} \mathrm{s}^{-1}$ e $\mathrm{T}_{\mathrm{bs}}$ é a temperatura de bulbo seco do ar em K.

$\mathrm{CTR}=\sigma \cdot 100^{4} \cdot\left[2,51 \cdot \sqrt{\mathrm{V}} \cdot\left(\mathrm{T}_{\mathrm{gn}}-\mathrm{t}_{\mathrm{bs}}\right)+\left(\frac{\mathrm{T}_{\mathrm{gn}}}{100}\right)^{4}\right]$

Outro índice que ultimamente tem sido usado para classificação do ambiente térmico em galpões de criação de frangos de corte é a entalpia (H) (equação 3). Segundo Barbosa Filho (2004), os limites de H considerados ideais para as aves estão entre 64 e $70 \mathrm{~kJ} \mathrm{~kg} \mathrm{de} \operatorname{ar} \operatorname{seco}^{-1}$. Sendo que, a entalpia é função da $\mathrm{t}_{\mathrm{bs}}\left({ }^{\circ} \mathrm{C}\right)$ e UR $(\%)$.

$$
H=6,7+0,243 \cdot t_{b s}+\left\{\frac{U R}{100} \cdot 10^{\frac{7,5 \cdot t_{b s}}{237,3+t_{b s}}}\right\}
$$

Os índices de conforto térmico são utilizados para quantificar e qualificar o desconforto térmico animal, que por sua vez, podem estar relacionados às respostas fisiológicas e desempenho produtivo das aves, sendo um método de avaliação indireto e relativamente prático.

Neste contexto, as avaliações de respostas fisiológicas e desempenho produtivo são formas de se avaliar a eficiência do sistema de criação e condições de bem-estar de frangos de corte. As variáveis a elas relacionadas sofrem interferência direta do ambiente interno de criação.

Objetivou-se com a presente pesquisa, avaliar o ambiente de produção de frangos de corte criados em galpões climatizados com diferentes sistemas de climatização por meio das variáveis relacionadas ao ambiente térmico, às respostas fisiológicas e ao desempenho produtivo das aves.

\section{METODOLOGIA}

\section{Caracterização dos galpões}

O experimento foi realizado no município de Itaberaí GO (16 $01^{\prime}$ S de latitude, $49^{\circ} 48^{\prime} \mathrm{W}$ de longitude, $722 \mathrm{~m}$ de altitude e pressão atmosférica de $929 \mathrm{hPa}$ ), entre os dias 17 de abril a 08 de maio de 2008, em dois galpões comerciais para a criação de frangos de corte: a) galpão equipado com ventilação em modo túnel (pressão negativa) e sistema de resfriamento evaporativo do tipo material poroso umedecido e nebulização (SRPN), cujo material poroso era composto por 2 placas de celulose $(10,70 \times 1,80 \mathrm{~m})$, além de 16 linhas de nebulizadores distribuídos ao longo do galpão, totalizando 89 emissores de água, com vazão média de 1,20 \pm $1,02 \mathrm{ml} \mathrm{s}^{-1} \mathrm{e}$ b) galpão equipado com ventilação em modo túnel (pressão negativa) e com o sistema de resfriamento do tipo material umedecido, com dois painéis cobertos por sombrite e umedecido por 47 nebulizadores (SRSN), distribuídos na região frontal às placas $(10,84$ x 2,00 m) associado com sistema de nebulização, composto por 17 linhas transversais, distribuídas ao longo do galpão, totalizando 94 emissores de água, com vazão média de 1,38 \pm $0,83 \mathrm{ml} \mathrm{s}^{-1}$. Os galpões SRPN e SRSN possuíam dimensões de 12 x 125 × 2,5 m e 13,65 x 125 x 2,5 m, respectivamente, e, ambos possuíam cobertura de telhas de cimento amianto (4 mm), alvenarias de tijolo furado, muretas laterais de 0,45 $\mathrm{m}$ de altura, piso de concreto, cama de palha de arroz reutilizada, tela de arame para fechamento lateral, cortinas laterais na cor azul, forro de cor amarela, três linhas de comedouros automáticos e quatro linhas de bebedouros tipo nipple. Os galpões, com orientação leste-oeste, possuíam como vegetação circundante bananeiras e coqueiros, sendo que renques de eucaliptos eram utilizados como quebra-ventos.

Internamente, os galpões estavam divididos em três regiões por meio de chapas de aço galvanizado com 0,4 $\mathrm{m}$ de altura, para evitar a movimentação das aves ao longo do galpão (Figura 1), sendo que foram alojados nesses galpões frangos de corte da linhagem Cobb, fêmeas, com densidade média de 13 aves $\mathrm{m}^{-2}$. No período de 21 a 43 dias de vida das aves, os sistemas de resfriamento funcionavam com 4 exaustores ligados constantemente nas horas mais quentes do dia (entre 10 às 18 horas), sendo que, quando a $\mathrm{t}_{\mathrm{bs}}$ atingia valores superiores a $29,5^{\circ} \mathrm{C}$, o segundo estágio do sistema de ventilação era acionado, totalizando 10 exaustores em funcionamento associados à nebulização. 


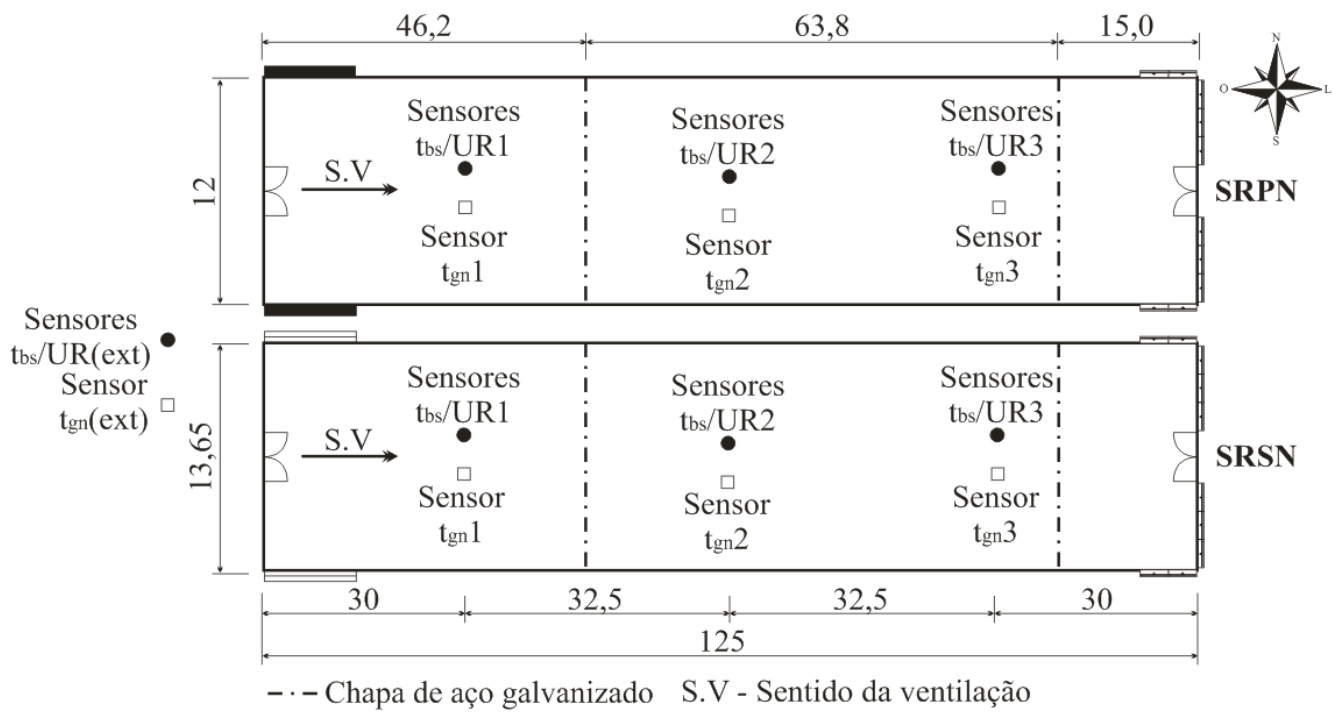

Figura 1 - Esquema de divisão da distribuição dos sensores / registradores para coleta de dados nos galpões. Unidade: m.

\section{Medição e instrumentação}

Os dois galpões foram monitorados continuamente do $21^{\circ}$ ao $43^{\circ}$ dia de vida das aves, correspondendo às fases de crescimento e final da produção, período no qual existe a necessidade de se fazer o resfriamento do ambiente no interior do galpão, a fim de se promover condições adequadas de produção, proporcionando assim, conforto térmico aos frangos de corte. As variáveis avaliadas foram as térmicas e as respostas fisiológicas e produtivas das aves.

O ambiente térmico foi avaliado por meio das variáveis $\mathrm{t}_{\mathrm{bs}}, \mathrm{T}_{\mathrm{gn}}$, UR e $\mathrm{V}$, sendo que as três primeiras foram medidas por sensores / registradores $( \pm 3 \%)$ programados para coletar estas variáveis ambientais em intervalos de 1 minuto. $\mathrm{A}_{\mathrm{gn}}$ foi medida por meio de sensores de temperatura introduzidos no interior de globos negros de plástico, pintados de preto fosco, previamente calibrados em relação a um globo negro de cobre padrão. Os sensores / registradores foram instalados em três seções a $0,3 \mathrm{~m}$ de altura, ao longo do comprimento de cada galpão, cujas distâncias em relação às placas de resfriamento foram 30 , 62,5 e $95 \mathrm{~m}$ (Figura 1). No caso de $\mathrm{V}$ foi utilizado um anemômetro de hélice digital $( \pm 3 \%)$.

As respostas fisiológicas (temperatura retal, TR; temperatura da pele, TP e frequência respiratória, FR) foram analisadas semanalmente, sendo que foram avaliadas 20 aves na primeira região, 30 na segunda e 10 na terceira (Figura 1), respeitando-se as subdivisões adotadas pela granja. Cada ave foi considerada uma repetição.

Para a medição da TR foi utilizado um termômetro digital com alta precisão $\left( \pm 0,1^{\circ} \mathrm{C}\right)$ e para medição da TP foi utilizado um termômetro infravermelho com regulagem de emissividade $\left( \pm 0,1^{\circ} \mathrm{C}\right)$. A FR foi determinada a partir da observação visual direta por 15 segundos e depois extrapolada para 1 minuto. As respostas produtivas avaliadas foram o consumo médio diário de ração (CRD), o ganho de peso médio diário (GPD), a conversão alimentar média (CA) e a taxa de mortalidade (TM).

\section{Delineamento experimental e análise estatística}

\section{Análise dos índices de conforto térmico}

O experimento foi instalado segundo o delineamento em blocos casualizados (DBC), em esquema de parcelas subdivididas. Na parcela, foi assumido um esquema fatorial 2 x 3 (2 galpões e 3 posições de coleta), sendo o fator tempo alocado na subparcela. Os dias de coleta, 22 dias no total, foram considerados como blocos. Sendo o efeito das posições de coleta significativo, optou-se por comparar as médias utilizando-se o teste de Scott-Knott. As análises de variância, o teste de médias e regressão linear, em função do tempo, das variáveis ambientais ( $\mathrm{t}_{\mathrm{bs}}$ e UR) e dos índices de conforto térmico (ITGU, CTR e $\mathrm{H}$ ) foram realizadas utilizando-se o software Sisvar 4.6 (Ferreira, 2000).

\section{Análise do desempenho animal}

Para a análise das variáveis de desempenho animal, o experimento foi instalado segundo o delineamento em blocos casualizados (DBC). Na parcela, foi assumido um esquema fatorial $2 \times 3 \times 4$ ( 2 galpões, 3 posições de coleta e 4 semanas avaliadas). Cada semana avaliada foi 
considerada como bloco. As análises de variância e regressão linear das variáveis do desempenho animal foram processados utilizando-se o software Sisvar 4.6 (Ferreira, 2000). No caso da TM, as medições foram realizadas diariamente, durante 22 dias, sendo cada dia considerado como um bloco.

\section{RESULTADOS E DISCUSSÃO}

\section{Ambiente térmico}

Não foi observada diferença estatística entre as variáveis relacionadas ao ambiente térmico nos galpões SRPN e SRSN ( $p>0,05)$. No entanto, verificou-se diferença significativa $(\mathrm{p}<0,05)$ entre os valores de ITGU, CTR e H nos horários de coleta. Dessa forma, a tendência estimada dos comportamentos de $\mathrm{t}_{\mathrm{bs}}$, ITGU, CTR e $\mathrm{H}$ ao longo do dia para as posições de coleta 1, 2 e 3 está ilustrada na Figura 2. Nessa figura foram adicionadas linhas que definem os limites inferior e superior de conforto térmico para frangos de corte que, no caso do ITGU, os limites são de 69,1 e 77,5, respectivamente (Oliveira Neto et al., 2000; Oliveira et al., 2006) e para H são de 64 e 70 kJ kg de ar seco-1 (Barbosa Filho, 2004).

As $t_{b s}$ internas aos galpões avaliadas, durante as horas mais quentes do dia, ou seja, das 10 às $18 \mathrm{~h}$, foram superiores à $26^{\circ} \mathrm{C}$ (Figura $2 \mathrm{~A}$ ), consideradas como limite superior de conforto (Baêta \& Souza, 1997; Tinôco, 2004), sendo que, de acordo com o teste de Scott-Knott, os valores de $t_{b s}$ nas posições de coleta 2 e 3 foram estatisticamente iguais e superiores aos valores médios observados na posição de coleta 1 .

Para o ITGU (Figura 2B), observa-se que o desconforto das aves amplia-se para praticamente todo o período do dia, devido, principalmente, à adição dos efeitos da radiação solar e velocidade do ar.

A CTR (Figura 2C) foi nitidamente superior na posição 3, o que foi confirmado com o teste de Scott Knott, sendo similar ao comportamento observado para $t_{b s}$ e ITGU em relação às posições 1 e 2 , confirmando a depreciação do ambiente térmico à medida que se afasta da extremidade de entrada do ar da extremidade de saída.

O comportamento de H (Figura 2D), nas três posições foi similar à $\mathrm{t}_{\mathrm{bs}}$ (Figura $2 \mathrm{~A}$ ), Entretanto, o período de desconforto ao longo do galpão foi ampliado em relação à $\mathrm{t}_{\mathrm{bs}}$, aproximando-se daquele observado para o ITGU (Figura 2B)

As condições térmicas na posição 1 foram estatisticamente inferiores (Scott Knott; $p<0,05$ ) que aquelas observadas nas posições 2 e 3, que são consideradas estatisticamente iguais (Scott Knott; p < 0,05). Entretanto, pela CTR, observou-se que a pior condição térmica foi observada na posição 3 (Scott-Knott; $\mathrm{p}<0,05)$, sendo que as posições 1 e 2 apresentaram condições estatisticamente iguais (Scott-Knott; $p>0,05$ ).
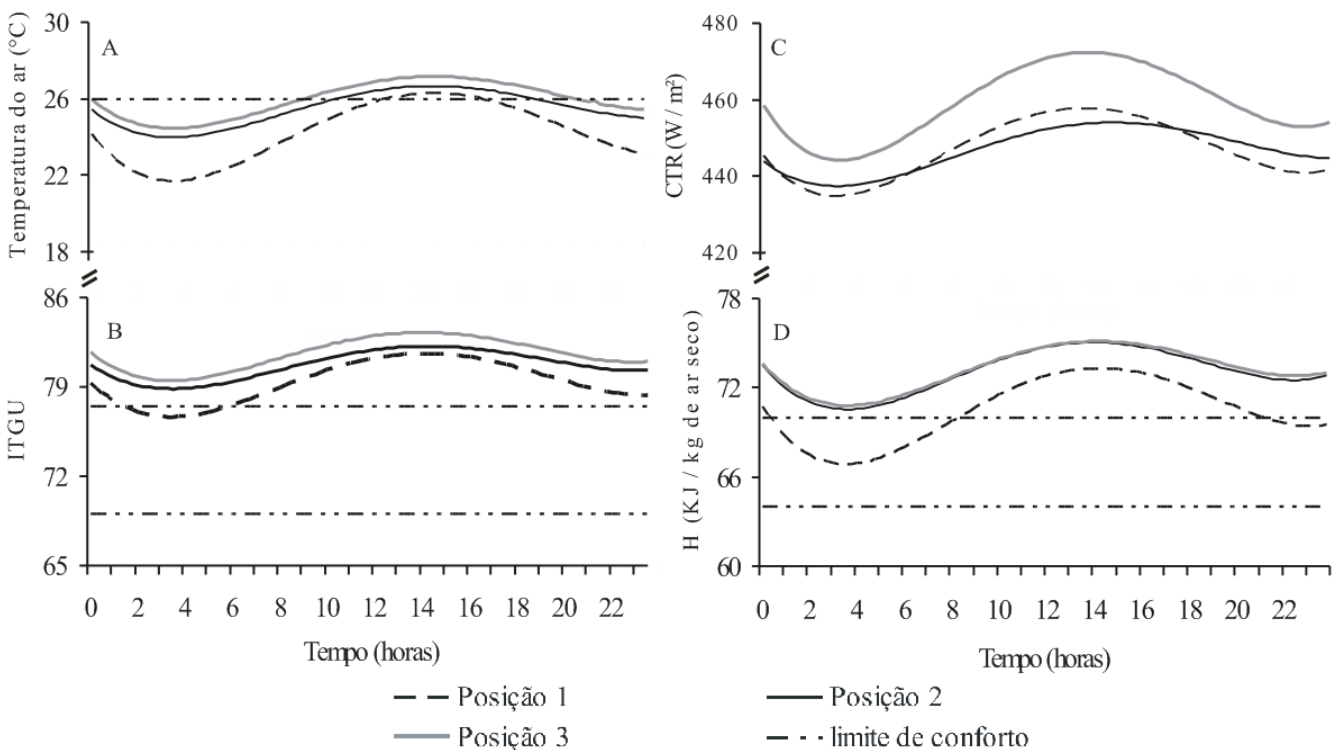

Figura 2 - Estimativas de temperatura do ar (A), índice de temperatura de globo negro e umidade (B), carga térmica de radiação (C) e entalpia (D) por meio de equações ajustadas em função dos horários do dia, nos galpões SRPN e SRSN para três das posições de medição. 


\section{Respostas fisiológicas}

Na Figura 3 estão apresentados os valores médios para TP, TR e FR associados aos valores médios de ITGU, $\mathrm{H}$, CTR e $\mathrm{t}_{\mathrm{bs}}$, nos galpões SRPN e SRSN, em cada semana avaliada.

Pode-se observar na Figura 3A que a TP nas $3^{\mathrm{a}}, 4^{\mathrm{a}}$ e $5^{\mathrm{a}}$ semanas de vida das aves, no galpão SRSN foi estatisticamente maior pelo teste $\mathrm{F}(\mathrm{p}<0,05)$. Isso deve ter ocorrido provavelmente em função da eficiência do sistema de resfriamento promovido pelo sombrite ser menor que aquela ocorrida na placa de resfriamento de celulose. Os valores médios das TPs, nos galpões SRPN, e SRSN ocorridos nesses dias foram 35,2 e $34,1^{\circ} \mathrm{C}$, respectivamente, para ITGU médio de $81,8, \mathrm{H}$ média de $73,4 \mathrm{~kJ}$ kg de ar seco-1, CTR média de $452,2 \mathrm{~W} \mathrm{~m}^{-2}$ e $\mathrm{t}_{\mathrm{bs}}$ média de $36,3^{\circ} \mathrm{C}$. Esses valores são inferiores aos encontrados por Yahav et al. (1997), cujo estudo realizado com frangos de corte machos da linhagem Cobb determinou valores de $39,7 \pm 0,2^{\circ} \mathrm{C}$, quando a temperatura externa foi de $26 \pm 1{ }^{\circ} \mathrm{C}$.

Os valores médios de TR, Figura 3B, foram estatisticamente iguais nos galpões SRPN e SRSN durante a $3^{\mathrm{a}}, 4^{\mathrm{a}}$ e $6^{\mathrm{a}}$ semana de vida das aves $(\mathrm{p}>0,05)$, sendo que na média foram $40,8^{\circ} \mathrm{C}$ e $40,9^{\circ} \mathrm{C}$, respectivamente, para ITGU médio de 83,2, $\mathrm{H}$ média de $75,1 \mathrm{~kJ} \mathrm{~kg}$ de $\operatorname{ar~seco}^{-1}$, CTR
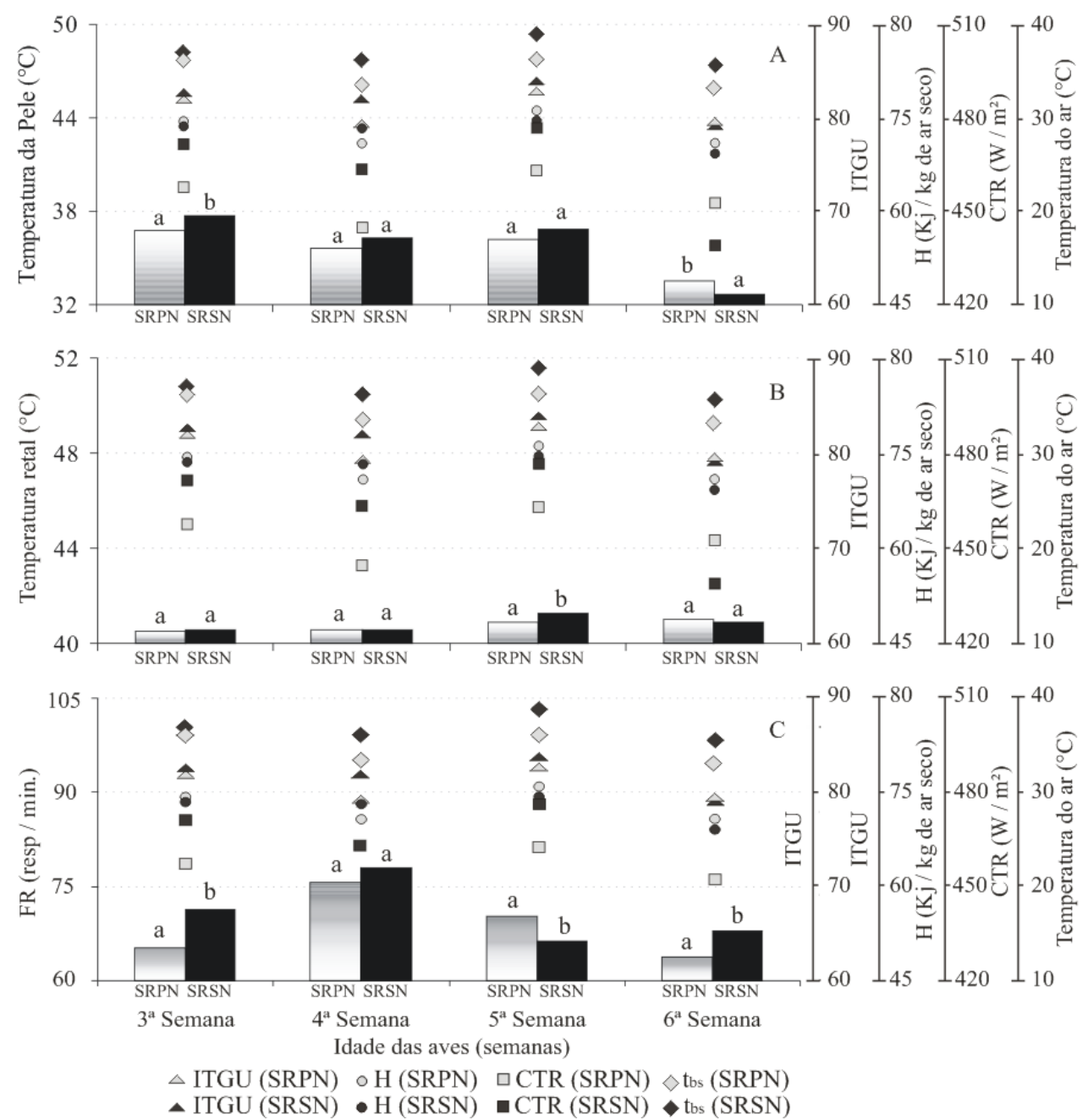

Figura 3 - Valores médios semanais de temperatura da pele (A), temperatura retal (B) e frequência respiratória das aves (C), com os respectivos valores médios, observados nos dias de coleta, de índice de temperatura de globo e umidade (ITGU), entalpia (H), carga térmica de radiação (CTR) e temperatura do ar ( $\mathrm{t}_{\mathrm{bs}}$ ), nos galpões SRPN e SRSN, ao longo do período experimental. As barras seguidas da mesma letra, não diferem entre si, pelo teste $\mathrm{F}(5 \%)$. 
média de $475,3 \mathrm{~W} \mathrm{~m}^{-2}$ e temperatura média do ar de $36,8^{\circ} \mathrm{C}$. Esses valores médios de TR são próximos ao intervalo de conforto térmico das aves, que é de $41,2^{\circ} \mathrm{C}$ a $42,2^{\circ} \mathrm{C}$ (Mount, 1979).

As FR nos galpões SRPN e SRSN, Figura 3C, foram estatisticamente iguais apenas na $4^{\mathrm{a}}$ semana de vida das aves ( $\mathrm{p}>0,05)$, sendo o valor médio encontrado ao longo do período avaliado, de 70,1 e 69,4 resp. min $^{-1}$, respectivamente, para ITGU médio de $80,9, \mathrm{H}$ média de $74,1 \mathrm{~kJ} \mathrm{~kg} \mathrm{de} \mathrm{ar} \mathrm{seco}^{-1}$, CTR média de 468,9 $\mathrm{W} \mathrm{m}^{-2}$ e temperatura média do ar de $35,2^{\circ} \mathrm{C}$. Esses valores são superiores ao mencionado por Medeiros (2001) que é de
40 resp. min..$^{-1}$, ao avaliar frangos de corte da linhagem Avian Farm em câmaras climáticas com a V igual a 1,5 m s -1 $^{-1}$ UR entre 35 e $85 \%$ e $\mathrm{t}_{\mathrm{bs}}$ em torno de 19 a $24{ }^{\circ} \mathrm{C}$.

Desse modo, verifica-se que, apesar da TR média indicar que os animais estavam em conforto, a FR revela que as aves já manifestavam algum sinal de estresse, depondo contra a sua condição de bem-estar.

\section{Desempenho produtivo}

De acordo com os valores médios de $\mathrm{CR}$, GP e CA, apresentados na Figura 4, verifica-se que não houve diferença significativa, pelo teste $\mathrm{F}$, entre os valores desses
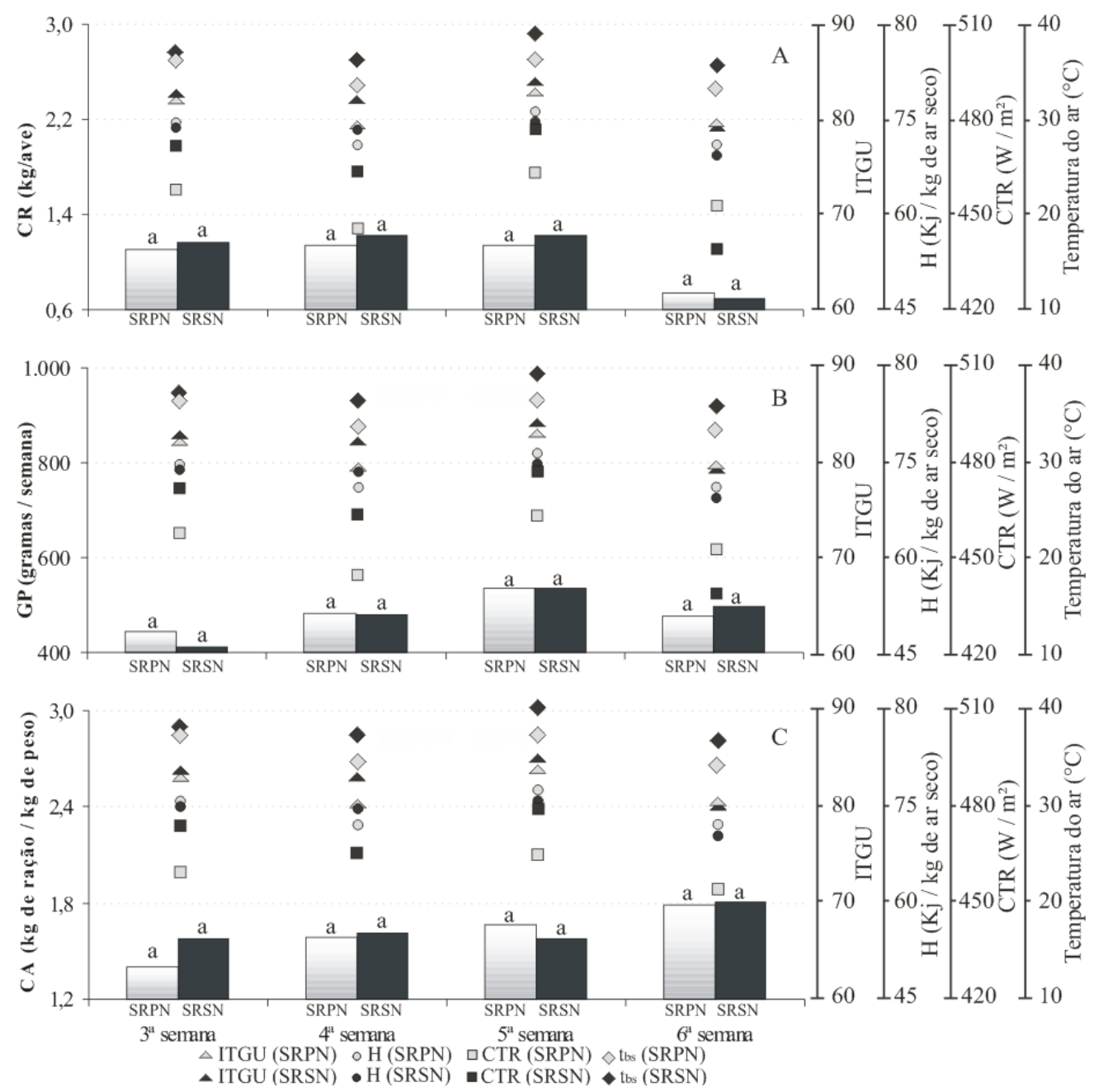

Figura 4 - Valores médios semanais de conversão alimentar (A), ganho de peso (B) e conversão alimentar (C), com os respectivos valores médios, observados nos dias de coleta, de índice de temperatura de globo e umidade (ITGU), entalpia (H), carga térmica de radiação (CTR) e temperatura do ar $\left(\mathrm{t}_{\mathrm{bs}}\right)$, nos galpões SRPN e SRSN, ao longo do período experimental. As barras seguidas da mesma letra, não diferem entre si, pelo teste $\mathrm{F}(5 \%)$. 
índices de desempenho produtivo entre os galpões avaliados ( $p>0,05)$, estando de acordo com os resultados obtidos para as variáveis relacionadas ao ambiente térmico. Entretanto, diferenças significativas foram observadas em cada sistema ao longo das semanas avaliadas $(\mathrm{p}<0,05)$.

Os CR médios finais das aves (Figura 4A) nos galpões SRPN e SRSN apresentaram valores de 2392 e $2384 \mathrm{~g}$, respectivamente. Esses valores foram inferiores ao encontrado por Moreira et al. (2003) que foi de $2818 \mathrm{~g}$, ao avaliarem o desempenho de frangos de corte, fêmeas, da linhagem Cobb 500.

O GP das aves nos galpões SRPN e SRSN foram 445,7 e 445,4 gramas semanas ${ }^{-1}$, respectivamente (Figura 4B). Esses valores são superiores aos encontrados por Furtado et al. (2006) que mencionam 377,3 gramas semanas ${ }^{-1}$, ao avaliarem o efeito de diferentes sistemas de acondicionamento sobre o desempenho produtivo de frangos de corte, de sexo misto, da linhagem Cobb.

Os valores médios de CA (Figura 4C), determinados para as aves durante o experimento, para os galpões SRPN e SRSN foram 1,61 e 1,64, respectivamente. De acordo com Cobb-Vantress (2008), a CA para frangos de corte da linhagem Cobb 500 é, aproximadamente, 1,70, próximo ao encontrado neste trabalho, sendo ligeiramente inferior ao encontrado por Pereira (2006), 1,76 e 1,79, ao avaliar frangos de corte de mesma linhagem, criados em galpões climatizados.

Durante o ciclo produtivo das aves, a mortalidade no galpão SRSN foi $15 \%$ maior em relação ao galpão SRPN, sendo que isso provavelmente deve ter ocorrido em função das piores condições térmicas observadas no galpão SRSN. A taxa de mortalidade final encontrada neste trabalho para o galpão SRPN foi de $3,4 \%$, enquanto que, para o SRSN foi de $3,7 \%$. Os valores encontrados são inferiores ao citado pela Cobb-Vantress (2008) que foi de aproximadamente 5\% para a linhagem avaliada. Esta tendência de comportamento foi verificada por Furtado et al. (2006) e Pereira (2006).

\section{CONCLUSÕES}

Com base nos resultados, pôde-se concluir que, apesar da região onde se situavam os galpões avaliados possuir clima quente principalmente no verão, os sistemas de resfriamento dos galpões estudados não foram capazes de garantir as condições de conforto ideais aos frangos de corte, o que foi comprovado pelos valores de FR e TR observados.

Apesar de terem sido verificadas algumas diferenças significativas das respostas fisiológicas das aves ao se compararem os dois sistemas estudados, nenhuma diferença foi observada nos índices zootécnicos. A TM no galpão SRSN foi $15 \%$ maior em relação ao galpão SRPN, porém, ambas são inferiores àquelas sugeridas para a linhagem em estudo.

\section{AGRADECIMENTOS}

À FAPEMIG, CAPES e CNPq pelo apoio financeiro à pesquisa.

\section{REFERÊNCIAS BIBLIOGRÁFICAS}

BAÊTA, F.C.; SOUZA, C.F. Ambiência em edificações rurais: conforto térmico animal. Viçosa, MG: UFV, 1997. $246 \mathrm{p}$.

BARBOSA FILHO, J.A.D. Avaliação do bem-estar de aves poedeiras em diferentes sistemas de produção $e$ condições ambientais utilizando análises de imagens. 2004. 123p. Dissertação (Mestrado em Física do Ambiente Agrícola)-Escola Superior de Agricultura "Luiz de Queiroz”, Universidade de São Paulo, Piracicaba, 2004.

BUFFINGTON, D.E.; COLLIER, R.L.; CANTON, G.H. Shade management system heat stress for dairy cows in hot, humid climates. Transactions of the ASAE, Saint Joseph, v.26, n.6, p.1798-1802, Nov./Dec. 1981.

\section{COBB-VANTRESS. Ten-year success story for leading}

German producer: technical cobb focus. Disponível em:

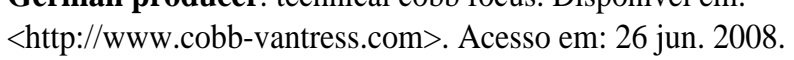

ESMAY, M.L. Principles of animal environment. 2.ed. West port: AVI, 1974. 325p.

FERREIRA, D F. SISVAR - Sistema de análise estatística para dados balanceados. Lavras: UFLA/DEX, 2000.

\section{FURTADO, D.A.; DANTAS, R.T.; NASCIMENTO,} J.W.B.; SANTOS, J.T.; COSTA, F.G.P. Efeitos de diferentes sistemas de acondicionamento ambiente sobre o desempenho produtivo de frangos de corte.

Revista Brasileira de Engenharia Agrícola e Ambiental, Campina Grande, v.10, n.2, p.484-489, 2006.

MEDEIROS, C.M. Ajuste de modelos e determinação de índice térmico ambiental de produtividade para frangos de corte. 2001. 115p. Tese (Doutorado em Engenharia Agrícola)-Universidade Federal de Viçosa, Viçosa, 2001. 
MOREIRA, J.; MENDES, A.A.; GARCIA, E.A.; OLIVEIRA, R.P.; GARCIA, R.G.; ALMEIDA, I.C.L. Avaliação de desempenho, rendimento de carcaça e qualidade da carne do peito em frangos de linhagens de conformação versus convencionais. Revista Brasileira de Zootecnia, v.32, n.6, p.1663-1673, 2003.

MOUNT, L.E. Adaptation to thermal environment. Baltimore: University Park, 1979. 333p.

OLIVEIRA, R.F.M.; OLIVEIRA, R.F.M.; DONZELE, J.L.; CECON, P.R.; VAZ, R.G.M.V.; ORLANDO, U.A.D Efeitos da temperatura e da umidade relativa sobre o desempenho e o rendimento de cortes nobres de frangos de corte de 1 a 49 dias de idade. Revista Brasileira de Zootecnia, Viçosa, v.35, n.3, p.797-803, 2006.

OLIVEIRA NETO, A.R.; OLIVEIRA, R.F.M.; DONZELE, J.L.; ROSTAGNO, H.S.; FERREIRA, R.A.; MAXIMIANO, H.C.; GASPARINO, E. Efeito da temperatura ambiente sobre o desempenho e características de carcaça de frangos de corte alimentados com dietas controladas e dois níveis de energia metabolizável. Revista Brasileira de Zootecnia, Viçosa, v.29, p.183-190, 2000.

PEREIRA, A.K. Fatores térmicos ambientais e qualidade do ar no desempenho produtivo de frangos de corte criados em alta densidade sob sistemas de ventilação positiva. 2006. 76p. Dissertação (Mestrado em Engenharia Agrícola)-Universidade Federal de Viçosa, Viçosa, 2006.

SAINSBURY, D. Sanidad y alojamientos para animales. Barcelona: Continental, 1971. 196p.

TINÔCO, I.F.F. A granja de frangos de corte. In: MENDES, A.A.; NÄÄS, I.A.; MACARI, M. (Eds.). Produção de frangos de corte. Campinas: FACTA, 2004. p.55-84.

YAHAV, S.; STRASCHNOW, A.; PLAVNIK, I.; HURWITZ, S. Blood system response of chickens to changes in environmental temperature. Poultry Science, Savoy, v.76, n.4, p.627-633, Apr. 1997.

YOUSEF, M.K. Stress physiology in livestock. Poultry Science, Boca Raton, v.3, p.159, 1985. 